\title{
Students and instant messaging: a survey of current use and demands for higher education
}

\author{
Gijs de Bakker*, Peter Sloep and Wim Jochems
}

Fontys University of Applied Sciences, The Netherlands

Instant messaging (IM) is the term used to describe the technology through which 'users can set up a list of partners who will be able to receive notes that pop up on their screens the moment one of them writes and hits the send button'. While early use could be described as mainly for fun, IM today is a serious communication medium. Remarkably, it seems that educational institutions have been doing very little with it, while several studies indicate that it could indeed be a valuable tool in education. As a first step towards a better understanding of the educational use of IM, we want to gain insights in how students currently use IM and what opportunities they themselves see for the medium. To that end we conducted a survey among students of the Fontys University of Applied Sciences in The Netherlands. A large majority of the participating students indicated using IM for their studies. Also, when asked about their demands for a possible educational implementation, the majority were positive.

\section{Introduction}

Instant messaging (IM) is the term used to describe the technology through which 'users can set up a list of partners who will be able to receive notes that pop up on their screens the moment one of them writes and hits the send button' (Castelluccio, 1999 , p. 34). IM contrasts with synchronous chat in this respect, since this is usually organised through publicly accessible chat rooms. Dating back to the moment the first computer networks were available in the 1970s, messaging experienced significant growth in the late 1990s via the rapid growth of AOL's Instant Messenger in the United States and the MSN Messenger system in Europe, both of which provided free consumer applications for IM. While early use of the tool could be characterised as being for fun, IM today is more usually considered to be a serious communication

\footnotetext{
*Corresponding author. Eindhoven School of Education: Fontys University of Applied Sciences, Technical University of Eindhoven, Traverse 3.42, Den Dolech 2, 5612 AZ Eindhoven, The Netherlands. Email: g.debakker@fontys.nl
} 
medium. Especially among young people, it has become one of the primary communication means (PEW Internet, 2004, 2005; Qrius, 2005), with its own culture and language.

Commercial organisations are aware of this development as well, but in our experience educational institutions have been very reluctant about adopting this medium. For example, many schools consider instant messaging as a mere fun tool for children in their spare time, and some even ban it from any school activity. Also, the research field of educational technology shows only a small number of studies on IM, as compared with other tools such as web-logging and communities. Several studies indicate that IM can indeed be a valuable tool in current education, which has changed its approach from being top-down organised to a more bottom-up approach based on social-constructivist theories and competence-based education. In this new educational model, IM could for example be used by students to practice their language proficiency skills with distant fellow-students (Coniam \& Wong, 2004). Other possible implementations are synchronous tutor guidance through IM or students using IM to reflect on fellow-students' work. Social developments, and especially the current ICT adoption wave among youth (Prensky, 2001), should influence the choices one makes regarding the implementation of the medium in or outside our classrooms.

The few studies conducted on IM up until today, however, use relatively small sample sizes and have an explorative nature (for example, Nicholson, 2002; Coniam \& Wong, 2004). As a first step towards a better understanding of the possibilities for educational use of IM, we want to gain insights in how students currently use IM and what opportunities they see for the medium themselves. These insights are valuable, in order to be able to develop software that answers to user needs. To that end we conducted a survey among students of the Fontys University of Applied Sciences in The Netherlands. This article reports the results of this study.

\title{
Instant messaging defined
}

For those unfamiliar with instant messaging, Castellucio's definition mentioned in the Introduction might not be sufficient. Grinter and Palen use the following, more elaborate description:

\begin{abstract}
IM systems support Internet-based synchronous text chat, with point-to-point communication between users on the same system. A window is dedicated to the conversation, with messages scrolling upward and eventually out of view as the conversation ensues. IM also supports group chat, with users inviting others to join them in a specified 'room.' Some systems, such as AIM and ICQ, make some chat rooms public. In some IM systems, pictures and URLs can be included in the messaging. Colors and fonts are personalizable. 'Buddy' lists display information about IM cohorts. Buddies' on-line handles (usernames) are displayed, along with indicators of activity (usually as a function of input device use) and availability (as inferred by activity and as stated explicitly by user-specified settings). Buddies can be sorted into user-defined categories such as 'friends,' 'family,' 'co-workers' and so forth. (2002, p. 21)
\end{abstract}

In this description, IM is limited to text-based communication. However, most IM systems now offer audio and video chatting functionalities as well. Also, IM is not 
limited to one-to-one communication. Users can add additional users to create group conversations. In most cases, the IM communication is handled through a software application installed on a users' computer. The majority of this software is free. Popular messaging systems are MSN Messenger (which recently migrated to Windows Live Messenger), AOL Instant Messenger, Yahoo! Messenger, Skype, Google Talk and ICQ. This last one initiated a popularity boost among Internet users in the second half of the 1990s. However, most of the current IM systems are (partly) based on an older online chat medium: Internet Relay Chat.

Together, Wikipedia estimates that IM systems currently have over 250 million active users. Most systems use their own protocol, which prevents them from being interoperable. So users with an AOL account cannot communicate with MSN users. Several attempts, for example by The Internet Engineering Task Force, to adopt a single, open, newly developed standard protocol have failed; it is only recently that Yahoo and Windows Live have opened up their protocols for each other. Interoperability will probably be one of the main challenges for IM's lasting success.

\section{Social developments: youth and instant messaging}

The number of active IM users (approximately 250 million worldwide) shows the success of the medium in the short period (since the late 1990s) it has been available to the public. Especially among teenagers, IM has become one of the most important communication means. More than $70 \%$ of today's youth uses IM, as surveys in the United States (12-17 year olds) and The Netherlands (6-29 year olds) show (PEW Internet, 2005; Qrius, 2005). According to the American research, only $44 \%$ of the adults used the medium. Furthermore, the Dutch survey showed that IM shares first place with email as the most popular activity for teenagers when online. The medium is used on a much more serious level than many adults might think. Through IM, teenagers communicate with their friends, make appointments, date (PEW Internet, 2001) and collaborate on school tasks (Grinter \& Palen, 2002). Teenagers do about everything online through IM, since 'the buddy list is teens' social world' (Boneva et al., 2006). The rising popularity of social networking websites such as Facebook and MySpace (PEW Internet, 2007), which incorporate IM functionality into their systems, makes it even easier for teenagers to meet new social contacts online.

Grinter and Palen (2002) point out that examining this development of IM usage among teenagers provides valuable insights. IM is the first and most successful form of social software that has entered into the public's lives. Studying the way in which the younger generation uses it, teaches us about its 'role in domestic ecology'; also, the 'communication habits they develop now may indicate what we can expect from them as adults' (Grinter \& Palen, 2002, p. 22).

\section{Instant messaging and education}

The studies on IM use mentioned indicate that youths already use the medium for educational activities. As already indicated, however, education has been neglecting 
the serious medium it has grown up to be. This might indicate that IM would not be a suitable medium for education, but there are strong arguments to the contrary. For example, Farmer (2005) conducted an IM experiment among students, concluding that they had a positive attitude towards the medium. However, empirical results are available as well. A survey among students of the Syracuse University School of Information Studies in New York showed that students benefited from the use of IM as a tool for socialisation with fellow students outside lectures (Nicholson, 2002). Several studies have shown the value of the implementation of IM as an online library referencing service (Foley, 2002; Andrews, 2004; Cummings \& Guerlain, 2004; Fagan, 2004; Johnson, 2004). Coniam and Wong (2004) tested IM as a tool for language proficiency training between students from different countries. Although the measured quantitative differences were not statistically significant, a qualitative analysis showed improvements in the language proficiency skills of the participating students. Hrastinski (2006) showed that adding IM to an asynchronous distance learning course stimulated student participation.

However, to enable education to determine the real benefits of IM, more empirical evidence is needed. Our future research will focus on identifying and exploring opportunities for IM in class. To avoid the pitfall of implementing information and communication technologies solutions that are not sufficiently based on actual demands, we first want to have better insights in how students currently use IM and what their wishes are for its use in education. For example, if students would state that they are willing to use IM for consultation with teachers, but not for online collaboration with fellow students, we should take that into account in the design of an experiment of educational IM applications.

Previously, several surveys have been conducted on IM use among youth (PEW Internet, 2005; Qrius, 2005). However, these studies did not provide data on educational use. At the same time, the few surveys conducted specifically on educational IM use (Grinter \& Palen, 2002; Nicholson, 2002; Farmer, 2005; Boneva et al., 2006), and the experimental studies on IM use available (Andrews, 2004; Coniam \& Wong, 2004; Fagan, 2004), used relatively small sample sizes and, in most cases at least, consisted of user experience and appreciation data. A larger study therefore is needed to get a better indication of students' IM use. Such a study should also gauge students' demands for the implementation of IM in their studies, as such data are also so far conspicuously lacking. To serve these ends, a survey was conducted among students at a Dutch institution for higher education.

\section{The study}

\section{Participants}

All participants were students at the Fontys University of Applied Sciences in The Netherlands. A number of its institutes were willing to forward a request mail to their students. Participants had to fill in their institutional personal identification number at the start of questionnaire, to prevent them from completing the online form more 
than once (they might want to do so in order to have a better chance at winning the lottery prize made available to them for maximising the response). Eventually, 376 male and 405 female students participated. They were aged 16-57 years. The participants came from various studies in arts, science and humanities.

\section{Materials and procedures}

Based on the motive for this initial IM study, we analysed students' perspectives rather than examining what they are actually doing. A questionnaire with mainly multiple-choice questions was set-up. The questionnaire was based on questionnaires used in previous studies on IM use (PEW Internet, 2001; Grinter \& Palen, 2002; Boneva et al., 2006), with additional questions added.

The questionnaire was published online on a separate web space of the Fontys institute's website. Students received an email with an explanation of the study, and the request for completing the online form. Also, a news item was published on the institute's intranet to attract more people to the survey website. In total, approximately 4500 students were approached. Some of these received an email, which resulted in an initial response of 668 completed forms. After the news item was published on the institute's intranet website, an additional 113 responses came in, providing a total of 781 responses. Thus, the response rate was $17 \%$. This is a fairly low percentage, which we feel is due to the non-committal way respondents were approached.

\section{Results}

The results are organised in terms of the specific aspects of IM usage we were looking for: IM use frequency patterns, technological specifications of users' environments, social aspects of IM usage and school use. Finally, the results of the specific questions asked on students' views on educational implementation of the medium are described. In order to find out whether generation differences show different results, the data were analysed using a Pearson product moment analysis.

\section{Instant messaging use frequency patterns}

The survey shows that $96 \%$ of all respondents used IM. In this group, $74 \%$ indicated they used IM on a (nearly) daily basis: five to seven days a week. These data correspond to a previous Dutch IM survey (Qrius, 2005) and American survey results on Internet use (PEW Internet, 2005). Female students used the medium more often than their male colleagues. It could be argued that IM use develops over time. Forty-eight per cent of the respondents using IM indicated that they used the medium more often compared with the first time they used it. However, at the same time, $34 \%$ used it less often.

Possible differences between disciplines were also examined. As the disciplines were so diverse, we were only able to compare science students (e.g. physics, natural sciences, computer science, etc.) with the rest of the student population (e.g. history, 
languages, economics, etc.). Technological tools such as IM are at first often mainly used by technophiles, before becoming widespread among a larger public. In contrast with what people might expect, however, the science students (often considered to be the technophiles compared with other students) did not use IM more intensively than the other students, as Table 1 shows.

IM is usually used in between other computer activities (65\%). When taking the time for it, only $24 \%$ of chats last longer than one hour. Also, most participants indicated that on an average day they do not talk to more than 10 people $(95 \%)$. The majority of the communication is done in separate conversations; only $3 \%$ of the respondents stated they used the group conversation functionality in their IM system regularly. It can be argued that IM is characterised by short sessions and a fragmented use throughout the day.

Although the questionnaire had options for respondents to note that they were not using IM at all, very few ( $8 \%$ ) did. This prompts the question whether IM users are more than proportionally present among the respondents (selection bias). As it is to be expected that people who actually use the medium already respond differently from those who do not, one should only carefully extrapolate results to the entire population. This issue should be taken into account in future research. However, other surveys, which used respondent approaching procedures that guaranteed a more balanced population, show similar IM use figures (Qrius, 2005). A survey specifically on IM use in the United States showed lower use frequency percentages (PEW Internet, 2004), but this used an adult sample only.

\section{Technological specifications of users' environments}

In The Netherlands, IM is often being referred to as 'MSN-ing', since MSN Messenger/Windows Live Messenger is the most popular service in the country. The survey results confirm this, $99 \%$ of the IM-using respondents uses this messaging system. Almost one-quarter of all students (24\%) also use Skype. Other less frequently used systems are ICQ, Google Talk, Internet Relay Chat, AIM (the most used system in the United States) and Yahoo messenger. Mac users also mentioned

Table 1. IM use frequency of science students, compared with the rest of the population

\begin{tabular}{lcc}
\hline & $\begin{array}{c}\text { Percentage of } \\
\text { science students }\end{array}$ & $\begin{array}{c}\text { Percentage of the rest } \\
\text { of the population }\end{array}$ \\
\hline No answer & 0 & 1 \\
Never & 3 & 2 \\
Once a month & 5 & 2 \\
Once a week & 7 & 5 \\
Two to four days a week & 15 & 16 \\
Five to seven days a week & 69 & 73 \\
Do not know & 1 & 1 \\
\hline
\end{tabular}


iChat, Adium and GAIM, all of which are multi-protocol applications (i.e. through these applications, users can use several IM protocols).

When asked about their computer facilities, students indicated having the following hardware: headset (40\%), webcam (58\%), microphone (53\%) and speakers (92\%). However, the availability of hardware does not mean that it is actually being used for IM purposes. The majority of respondents mainly use text chatting. Voice and video chat are being used 'sometimes' by $33 \%$ and $44 \%$, respectively, and more than onehalf of the respondents 'never' use either.

Two places are most popular for using IM: at home on a students' personal computer $(78 \%)$ and in school $(69 \%)$. Other places are at home on a shared computer $(42 \%)$, at a friend's house $(18 \%)$ or at work $(11 \%)$. Only $8 \%$ of the students use IM on a mobile device.

\section{Social aspects of instant messaging usage}

Most students have quite an extensive buddy list (IM contact list). One-third of all students have more than 100 friends in their messenger list. Also, people who use IM more regularly have a larger contact list. Although these are impressive figures, Danah Boyd argues these online friends have a different status to real-life friends (Boyd, 2006). A large number of students (36\%) indicated that they would have a hard time missing the availability of IM.

Students tend to treat the medium rather freely. Sixty-eight per cent of all respondents have ignored messages in the past, and $88 \%$ have even blocked contacts in their buddy list (making it impossible for those contacts to see or talk to them).

Conversation topics are very diverse. Table 2 presents the survey conversation topic categories and the percentage of participants using them.

\section{School use and students' views on educational implementation of IM}

The majority of students (89\%) used IM for one or more study activities; $67 \%$ even used it for five or more of the study activities mentioned in the questionnaire. When

Table 2. IM conversation topics (excluding educational use) and Dutch higher education students using them (\%)

Topic

Percentage of students using topic

Talking casually to family and friends seen rarely 82

Talking casually to family and friends seen often

Making appointments with family and friends

Discussions with family and friends

Playing games 
asked whether the students wanted IM to be implemented in their education, most students $(86 \%)$ indicated they wanted to use IM in their education. Almost one-half of the students mentioned more than five activities they would like to see in educational IM. Table 3 presents the educational IM activities mentioned in the survey and the percentages of students using them already personally. The last column represents the percentage of students that would like to see these activities being implemented in their education. Differences between actual and desired use are small, with the exception of teacher guidance.

\section{Generation differences}

The age of the respondents ranged from 16 to 57 years, but the majority was 19-21 years old ( $43 \%$ of the respondents). The survey showed some interesting correlation effects between certain aspects of IM use and demands, and the age of the respondents. We will limit ourselves to describing only the correlations that proved significant ( $\alpha=0.01$ ). In general, younger students are more intensive IM users. They used the medium more often that the older students $(r=-0.389)$, had more buddies $(r=-0.429)$ and used it when connected to the Internet more often $(r=-$ $0.283)$. Also, they talked to more people in one day $(r=-0.326)$. When looking at technical specifications, we did not find a significant effect of age. However, younger students seem to replace text-based messaging by audio and video alternatives more often $(r=-0.205)$. When asked whether the respondent would like to make more use of IM, it turned out that the older students were more interested in doing so $(r=0.194)$.

On the educational use of the medium, we did not find major differences between ages, apart from the younger students discussing school tasks more with their fellow

Table 3. Educational IM activities and demands of Dutch higher education students

\begin{tabular}{lcc}
\hline Educational activity & $\begin{array}{c}\text { Percentage of students } \\
\text { using personally }\end{array}$ & $\begin{array}{c}\text { Percentage of students that would } \\
\text { like to see implementation }\end{array}$ \\
\hline $\begin{array}{l}\text { Discussing school tasks with fellow } \\
\text { students }\end{array}$ & 85 & 85 \\
$\begin{array}{l}\text { Sharing files (such as report } \\
\text { concepts or sketches) }\end{array}$ & 71 & 74 \\
$\begin{array}{l}\text { Cooperating on school tasks with } \\
\text { fellow students }\end{array}$ & 63 & 76 \\
$\begin{array}{l}\text { Discussing course material with } \\
\text { fellow students }\end{array}$ & 61 & 59 \\
$\begin{array}{l}\text { Gathering content, such as course } \\
\text { material }\end{array}$ & 44 & 55 \\
$\begin{array}{l}\text { Reflecting on fellow students' work } \\
\text { Teacher guidance }\end{array}$ & 36 & 45 \\
Other & 1 & 34 \\
\hline
\end{tabular}


students $(r=-0.076)$. This result, however, was only significant at a lower level ( $\alpha=$ 0.05). Educational demands did show some interesting differences. In general, a larger number of the younger students would like to see an educational implementation of IM in the future. Four out of the nine categories of educational IM use students could chose from for indicating their use for those purposes showed a negative correlation with age. Those categories were 'discussing school tasks with fellow students', 'cooperating on school tasks with fellow students', 'gathering content, such as course material' and 'sharing files (such as report concepts or sketches)'. Also, the option 'I do not want to use IM in my study' showed a positive correlation ( $r=$ 0.152), which indicates that older students are less willing to use the medium for educational purposes. When looking at the activities more specifically, the younger students would like to have more task discussions $(-0.100)$, collaboration $(-0.101)$, information gathering $(-0.116)$ and file-sharing $(-0.142)$ through IM.

\section{Conclusions and discussion}

In general, people who make more use of IM also use it longer, have a larger buddy list (IM contacts), and so on. Thus, the adoption wave does not seem to concentrate on specific aspects of IM usage. Perhaps one of the most interesting findings of this study is that younger students use IM more intensively than their older peers. Younger students are also keener on trying new possibilities of the medium. This indicates that the adoption of the medium is still developing. It would be interesting to see how this development continues. Will IM become the primary communication medium for everybody? A Dutch youth survey shows this is already the case for a certain age group (Qrius, 2005). It could also be that age plays a big role in the adoption of the medium. It might be a youth tool people tend to grow out of. This is a question that can only be answered as the current IM generation grows older. Looking at the recent corporate IM implementation wave, and the indicated usefulness of the medium in business contexts (Nardi et al., 2000), the latter it is not to be expected (Pauleen \& Yoong, 2001; Perry et al., 2001).

As noted previously, the survey might have attracted IM users mainly. This should be taken into account for future research. We could test our findings among a more naturally varied group of students. As this study was part of a research project into educational IM implementation possibilities, in future studies we will be analysing IM conversations more closely in order to gain insights into what educational IM conversations consist of in terms of content, communication style, and so on. In a later stage, we will also develop new applications or plug-ins for existing IM systems, which make educational use of IM more fit for current education, looking at recent changes such as self-directed learning. An example of such a new application is a peer-tutoring system, which enables students to get instant support from relevant fellow-students. This not only enables them to get their questions answered more quickly, it also reduces the workload for teachers, which has increased due to the introduction of the social-constructivist theories in learning (De Vries et al., 2005). 
Above all, the survey shows that education cannot simply ignore the importance of IM. Today's students embrace the medium, and would like to see it being implemented in their learning environment. Early empirical research has shown that IM might be a useful tool, but the simple fact that students demand the medium's implementation should be enough reason for education to consider that. The fact that only one-third of the population indicates that they would like to see teacher guidance being available via IM should be considered in such implementations. This might indicate that students are interested in the self-organised bottom-up nature of the medium, which should be preserved when institutionalising it.

\section{References}

Andrews, K. W. (2004) What are they asking and why are they asking it? Usage patterns of an AOL Instant Messenger chat reference service. Unpublished Master thesis, University of North Carolina, Chapel Hill, NC. Available online at: http://etd.ils.unc.edu/dspace/retrieve/ 461/kristinandrews.pdf (accessed 10 August 2006).

Boneva, B., Quinn, A., Kraut, R., Kiesler, S., Cummings, J. \& Shklovski, I. (2006) Teenage communication in the instant messaging era, in: M. B. R. Kraut \& S. Kiesler (Eds) Domesticating information technology (Oxford, Oxford University Press), 201-218.

Boyd, D. (2006) Friends, friendsters, and top 8: writing community into being on social network sites, First Monday, 11(12). Available online at: http://www.firstmonday.org/issues/issue11_ 12/boyd/index.html (accessed 21 December 2006).

Castelluccio, M. (1999) E-mail in real time, Strategic Finance, 81(3), 34-37.

Coniam, D. \& Wong, R. (2004) Internet Relay Chat as a tool in the autonomous development of ESL learners' English language ability: an exploratory study, System, 32(3), 321-335.

Cummings, J. \& Guerlain, S. (2004) Using a chat interface as an embedded secondary tasking tool, paper presented at the Human Performance, Situation Awareness and Automation Technology II Conference, Daytona Beach, FL. Available online at: http://web.mit.edu/aeroastro/www/people/ missyc/pdfs/CummingsHPSAA04.pdf (accessed 10 August 2006).

De Vries, F., Kester, L., Sloep, P., Rosmalen, P. v., Pannekeet, K. \& Koper, R. (2005) Identification of critical time-consuming student support activities in e-learning, Research in Learning Technology (ALT-F), 13(3), 219-229.

Fagan. (2004) Creating an instant messaging reference system, Information Technology and Libraries (ITAL), 20(4), 202-212.

Farmer, R. (2005) Instant messaging, Educause Review, 40(6), 48-62.

Foley, M. (2002) Instant messaging reference in an academic library: a case study, College and Research Libraries, 63(1), 36-45.

Grinter, R. \& Palen, L. (2002) Instant messaging in teen life, paper presented at CSCW'02, New Orleans, LA, 16-20 November, pp. 21-30.

Hrastinski, S. (2006) Introducing an informal synchronous medium in a distance learning course: how is participation affected?, The Internet and Higher Education, 9, 117-131.

Johnson, C. M. (2004) Online chat reference, Reference E User Services Quarterly, 43(3), 237-247.

Nardi, B. A., Whittaker, S. \& Bradner, E. (2000) Interaction and outeraction: instant messaging in action, paper presented at the Computer Supported Cooperative Work Conference, Philadelphia, PA, 2-6 December.

Nicholson, S. (2002) Socialization in the 'virtual hallway': instant messaging in the asynchronous web-based distance education classroom, The Internet and Higher Education, 5(4), 363-372. 
Pauleen, D. J. \& Yoong, P. (2001) Facilitating virtual team relationships via Internet and conventional communication channels, Internet Research: Electronic Networking Applications and Policy, 11(3), 190-202.

PEW Internet (2001) PEW Internet project report: teenage life online (Washington, DC, PEW). Available online at: http://www.pewinternet.org/pdfs/PIP_Teens_Report.pdf (accessed 15 August 2006).

PEW Internet (2004) PEW Internet project report: the internet and daily life (Washington, DC, PEW). Available online at: http://www.pewinternet.org/pdfs/PIP_Internet_and_Daily_Life. pdf (accessed 16 March 2007).

PEW Internet (2005) PEW Internet project report: teens and techonology (Washington, DC, PEW). Available online at: http://www.pewinternet.org/pdfs/PIP_Teens_Tech_July2005web.pdf (accessed 14 March 2005).

PEW Internet (2007) PEW Internet project report: social networking websites and teens: an overview (Washington, DC, PEW). Available online at: http://www.pewinternet.org/pdfs/PIP_SNS_ Data_Memo_Jan_2007.pdf (accessed 16 March 2007).

Perry, M., O'Hara, K., Sellen, A., Brown, B. \& Harper, R. (2001) Dealing with mobility: understanding access anytime, anywhere, ACM Transactions on Computer-Human Interaction, 8(4), 323-347.

Prensky, M. (2001) Digital natives, digital immigrants, On the horizon, 9(5), 1-6.

Qrius (2005) fongeren 2005, youth research report (Amsterdam, Qrius). Available online at: http:// www.hetjongerenonderzoek.nl/pdf/Inleiding2005(kort).pdf (accessed 18 August 2006). 